\title{
INTANGIBLE CULTURAL HERITAGE IN THE PACIFIC ISLANDS: WHY EUROPE SHOULD LISTEN IN
}

\author{
K.A. Serrano a \\ a University of Central Lancashire, School of Law, Preston, PR1 2HE, England and \\ University of the South Pacific, PMB 9072, Port Vila, Vanuatu - Serrano_k@vanuatu.usp.ac.fj
}

KEY WORDS: Intangible Cultural Heritage, Pacific islands, Customs, Traditional Knowledge, Intellectual Property Rights, Economic Partnership Agreements, Development Policy.

\begin{abstract}
:
Pacific Island countries (PICs) are developing countries representing one of the culturally richest and most diverse regions worldwide. A decade ago, the realization evolved at international level that intangible cultural heritage (ICH) represents a development tool with an inherent commercial value. Regional initiatives are currently trying to balance objectives of development and protection of ICH with the need for commercial exploitation and effects of commodification. Yet, the same cannot be said about the Economic Partnership Agreement (EPA) between PICs and the EU. The article advocates that current EU efforts in supporting regional and national processes meant to establish a preliminary level of legal protection for Pacific ICH are insufficient and inappropriate to the 'living' character of ICH. It promotes a more context-oriented design of intellectual property rights (IPR) provisions in EU policy instruments aimed at sustainable development of the Pacific region.
\end{abstract}

\section{INTRODUCTION}

Pacific culture has often been described as "expressed through hundreds of languages, long-standing cultural traditions across largely dispersed island communities, works of Pacific art, and land sites of unique cultural importance for Pacific people" (Serrano and Stefanova, 2011). Marshallese navigational charts (rebbilib), Vanuatu's sand drawings (sandroing), Tuvaluan action songs known as faatele or Samoan traditional body tattoos, the pe'a, are but a few examples of the region's cultural wealth. While tangible cultural heritage has seen much publicity through its protection via United Nations Educational, Scientific and Cultural Organization (UNESCO) Heritage Sites ${ }^{*}$, currently only few island countries have put in place legal frameworks for the protection of their traditional knowledge (TK) and intangible cultural heritage (ICH). ${ }^{* *}$ Even where intellectual property rights (IPRs) are protected under conventional trademark or copyright legislation, these laws either do not consider ICH to the extent necessary for meaningful protection or they are incompatible with the complex nature of $\mathrm{ICH}$, rendering them inappropriate for its protection (Samoa Law Reform Commission, 2010).

Apart from inadequacy of existing legislation, a missing universal definition of ICH contributes to the infant state of ICH protection in the Pacific. While literature agrees on some common features and domains of $\mathrm{ICH}$, no exhaustive definition exists yet (Yahaya, 2006). ICH is often referred to as "knowledge [that] was generated, added upon and passed down the line by words, observations and practices" (Menaka, 2010). UNESCO defines ICH as "constantly recreated by communities

\footnotetext{
* There are currently seven officially inscribed UNESCO Heritage Sites in the Pacific, located in Fiji, the Marshall Islands, the Federated States of Micronesia, Papua New Guinea, Solomon Islands, Tonga and Vanuatu.

** The terms traditional knowledge and cultural property are used broadly and interchangeably in this article to reflect the definition in Article 2 of the Convention for the Safeguarding of the Intangible Cultural Heritage 2003.
}

and groups, in response to their environment, their interaction with nature, and their history" (UNESCO, undated) while Art. 2 of the 2003 Convention for the Safeguarding of the Intangible Cultural Heritage lists "practices, representations, expressions, knowledge, skills, instruments, objects, artefacts and cultural spaces associated with communities, groups and individuals" as domains belonging to ICH (UNESCO, 2003). At government level, definitions range from "non-material culture" to "cultural living heritage" and "folklore and ethnic culture" (UNESCO, 2011). The international practice then is to define content and scope of each reference at national level, in accordance with the distinct nature of each country's context, its historic development, socio-legal circumstances, natural habitat available to stakeholders et cetera. According to Yahaya, so far there are no signs that "the finer terminology of 'heritage' has (...) been streamlined or standardised, and thus no uniformity exists between countries" (Yahaya, 2006). The difficulties encountered in defining and protecting ICH reflect the fact that to date a sui generis system of ICH protection in the Pacific is missing, despite the PICs' global forerunner role in this area.

Yet, the struggle to ascertain meaningful and effective mechanisms of $\mathrm{ICH}$ protection seems not to impede on the ability of Pacific islanders to claim ownership of their cultural heritage at national level. Particularly since independence, national traditions, customs and values are cherished as part of the national identity of Pacific people and are heralded as such in almost all post-colonial Pacific societies. Pacific Constitutions reaffirm the link between identity of the people and their customs and traditions by endorsing that "...the happiness and welfare of the people (...), both present and future, depend very largely on the maintenance of (...) values, culture and tradition" (Constitution of Tuvalu 1986); Statements such as "[a]ll we have and are today as a people, we have received as a sacred heritage which we pledge ourselves to safeguard and maintain..." (Constitution of the Republic of the Marshall Islands 1979) reflect the idea of a generational contract as well as a sense of continuity that underlies Pacific societies. These testimonials document the historic importance of cultural heritage and its critical place in relation to the 
distinctiveness of Pacific people; they are also indicative of claims of ownership based on perceptions of community rather than being expressions of individual rights.

However, culture in the Pacific islands is still treated in isolation from other national policies such as trade, development, education, health or environment. International lobbying for these 'prime sectors' of Pacific governments over the past decade has been successful, thereby leaving little policy space for mainstreaming of culture. In Vanuatu, for example, the National Self Reliance Strategy 2020 demands that a "cultural impact assessment (...) be developed and implemented as a development planning tool required for all new development initiatives" (Malvatumauri National Council of Chiefs et al, 2005). Unfortunately, the Strategic Plan is merely a recommendation to the government and so far not much progress has been recorded in turning it into legally binding commitments. Consequently, in Vanuatu's Priorities and Action Agenda 2006-2015 there is no reference whatsoever to ICH as development tool (Vanuatu Government, 2006). As a result, national initiatives to streamline culture remain limited with a patchy picture of actions relevant to ICH. According to the Vanuatu Ministry of Education, there has been "some progress" in this area "but much remains to be done" due to "insufficient financial and human resources" at the disposal of the Ministry (Vanuatu Ministry of Education, 2012).

A decade ago, a common consciousness evolved that ICH may be utilized as an economic development tool with inherent commercial value. Countries like Korea, Ireland or China started to actively assist in the development of cultural industries and the utilization of cultural heritage for purposes of sustainable development. Here, ICH has become part of national economic development planning as well as an asset in industrial development plans. In England, for instance, the creative and cultural industries sector contributed $£ 57.3$ billion to the British economy (UK Local Government, 2009) while Thailand's creative industries contributed about USD 43 billion to the Thai economy in 2008 (Kenan Institute Asia, 2009). In comparison, Pacific island governments have only recently started realizing that Pacific ICH can not only be exploited to attract more tourism and enhance the 'Pacific paradise' value of the islands for foreign direct investment (FDI); it can also be used as tool for development through job creation, utilization of niche markets and formation of creative industries whose particular role in economic development has also been increasingly recognized within the cultural policy discourse (Hartley, 2005).

Representatives of PICs agree unequivocally at regional meetings that "while cultural industries contribute to economic development [in the Pacific islands], the sector still represents a largely untapped socio-economic potential" (Secretariat of the Pacific Community, 2010). However, commercial use of ICH in the Pacific, as elsewhere, is controversial and carries a particularly contentious note. Research demonstrates that commercial use of ICH outside its traditional context changes the perception of the communities themselves towards their own cultural heritage [17]. This so-called Dream Catcher Syndrome, closely related to notions of misappropriation and out-ofcontext commodification of culture, has been exhaustively discussed in Indian-American context where it led researchers to conclude that such commodification inevitably leads to a "loss of meaning" for the bearers of the tradition themselves (Osborne, 2003/2004). As a consequence, the element of culture is removed from its context and becomes a meaningless item, story or song without the significant cultural connotation that made it classify as ICH for the community in first place.
In the Pacific, the Dream Catcher Syndrome can be observed in many places. In Samoa, for example, body tattoos have a traditional meaning for the bearer and only certain families or tattooists (tufuga) may perform the customary, sacred act of tattooing (tatau) people of Samoan descent only. In the words of Makerita Urale, a Samoan tattoo artist and film director, "the traditional male [Samoan] tattoo, which extends from the waist to the knees, embodies the concept of serving the people. It's also a rite of passage and a symbol of bravery, because it's very bloody and it sometimes takes an entire year to complete" [18]. In recent times however, Samoan tattoos have become part of a "Pacific pop culture" with tourists and visitors to Samoa perceiving the tattoos as 'sexy' and collecting Samoan traditional body art as a kind of 'trendy souvenir' from the Pacific. In this sense, Samoan body tattoos, despite their value as pieces of art, are losing their traditional meaning through detachment from the original context; their content and unique justification for their existence has been lost to many Samoan traditionalists in the process of commercialization.

The above example, as many others, illustrates the obvious need for a coherent, streamlined and holistic approach to ICH protection in the Pacific. This is also true for PICs' international engagement with developed partners via multilateral trade and development treaties. These agreements often contain provisions with direct or indirect impact on the protection, development or commercial use of culture, including Pacific ICH. The Economic Partnership Agreement (EPA) between the European Union (EU) and PICs, building on the interim EPA signed by Papua New Guinea and Fiji in 2009, is a case in point. ${ }^{*}$ Based on Art 36 and Art 37 of the Cotonou Agreement (CA), the Pacific EPA is an agreement that will go beyond economic development and trade liberalization to include issues such as peace building, human rights, sustainable economic development and support for regional integration. It is understood that the latest draft of the Pacific EPA text also contains provisions on intellectual property rights (IPRs) relevant to the protection and management of ICH. As such, it constitutes a document that should be included in the debate surrounding Pacific ICH.

Protection of ICH is undisputedly crucial. However, the modes of protection and the various policy and legislative options present a complex picture of ICH. The multifaceted nature of Pacific societies, the colonial heritage within their legal systems as well as the diversity of issues hiding behind the mask of ICH are key parameters within which the article seeks to provide some recommendations in regard to the meaningful protection of ICH. In doing so, it contributes to a growing international literature examining the status and regulation of $\mathrm{ICH}$ in various parts of the world, including the Pacific region. Through the application of the 'Pacific lens' to ICH issues, it also supports the Pacific countries' pioneering role in setting international standards for ICH protection. In the following section, the

\footnotetext{
Due to the complexity of the agreement, several conclusion deadlines have been missed for the Pacific EPA which has been under negotiation since 2002. At the June 2012 EUACP meeting held in Port Vila, Vanuatu, Pacific leaders demanded that the EU embraces in good faith its responsibility to negotiate a comprehensive, developmentfriendly EPA with PICs. The latest available draft text dates back to June 2006 and does not contain any provisions related to IPRs yet. The last draft EPA text, including IPRrelated provisions, dates back to June 2011 but is unavailable to the public due to a missing response from the EU Commission.
} 
article will highlight some of the ICH relevant initiatives undertaken at regional level. Emphasis will be placed on regionspecific issues pertinent to the protection of ICH in legal pluralist environments of the PICs. Furthermore, the article will analyse the involvement of the EU in establishing a viable and meaningful regime of $\mathrm{ICH}$ protection in the Pacific islands. It will conclude with some recommendations for a contextorientated engagement of the EU with PICs at the intersection of the IPR, trade and development debate.

\section{INTANGIBLE CULTURAL HERITAGE: THE PACIFIC WAY}

In response to pressures of globalization, diminishing trade preferences and aid dependency, Pacific governments realized around 1999 in a trade-related context that Pacific ICH is a commercially exploitable 'commodity' in which PICs have a considerable relative trade advantage. What followed was recognition that, without proper protection and assignment of balanced and meaningful property rights, Pacific ICH was at imminent risk of misappropriation and excessive exploitation without appropriate compensation for traditional right owners, including individuals as well as communities. The trade context gave rise to some debate on how to manage and regulate Pacific ICH against the background of its 'living' nature. In a move towards an integrated design of IP-related legislation at national level, PICs developed three major regional initiatives of relevance for ICH: the Regional Framework for the Protection of Traditional Knowledge and Expressions of Culture (2002); the Traditional Biological Knowledge, Innovations and Practices Model Law (2008); and the Melanesian Spearhead Group's draft Treaty on Traditional Knowledge (2011).

All three regional models set out amendable framework provisions for protection of ICH at national level. So far, most PICs have chosen to implement the model laws in their national legislation. TK Legislation is at different stages of implementation in PICs, with Kiribati and Fiji having legislation already in place while others such as Palau and Nauru are still organizing resources for policy directions on TK legislation. Most countries have chosen different pathways to their legislation, with Fiji starting the process with a legislative proposal and Kiribati holding consultations first to arrive at policy instructions [19]. According to Forsyth, the diversity of approaches will result in very different pieces of legislation at national level, despite the Model Laws' call for a harmonious approach [19]. In the following section, the three main legislative initiatives at regional level will be discussed in brief to highlight parallels and differences in approach.

In 2002 the Framework Treaty on Traditional Knowledge and Expressions of Culture (TKEC) was endorsed by the Regional Meeting of Ministers of Trade under auspices of the Pacific Islands Forum Secretariat (PIFS). It is generally thought of as a major achievement in protecting Pacific ICH [20]. Based on a very broad, open-ended definition of TK and "expressions of culture" in Art. 4 as well as the relatively new concept of Traditional Cultural Rights (TCRs), the TKEC Framework Treaty is applicable to tangible and intangible cultural heritage without making this distinction expressis verbis. According to Marahare, "[t]he policy objective of the [Framework Treaty] is to protect the rights of traditional owners in their traditional knowledge and expressions of culture and to permit traditionbased creativity and innovation, including commercialization thereof, subject to prior and informed consent and benefitsharing [20]. The TKEC Framework Treaty was "designed with the circumstances of the Pacific in mind, expected to form the basis of a harmonized regional legal framework" [21]. Its main objective is to encourage sui generis legislation in PICs and to give policy makes a framework that can be adapted to individual national circumstances of each country in the region. The TKEC Framework Treaty uses a combination of legal forms of protection, such as exclusive property rights, moral rights, criminal offences and civil actions [21]. Furthermore, it permits commercial use of TCEK but ensures that this is based on prior informed consent of the traditional owners who are to be included in benefit-sharing on the basis of equitable, accessible, transparent contracts. In addition, it ensures that the rights granted are inalienable and continue in force in perpetuity.

The innovative elements of the TKEC Framework Treaty are thus threefold. First, it represents the earliest Pacific initiative to take TKEC out of the public domain and to allocate meaningful TCRs to traditional owners of TCEK. Second, it symbolizes a first balanced approach between ownership traditionally articulated through national IP policies, and stewardship based on cultural policy, including heritage and diversity policy. Third, it combines exploitation of ICH with the necessary protection for its context, present rightful owners and future generations of traditional custodians of ICH. As such, the Framework Treaty goes beyond a purely IP-based system of ICH protection by empowering communities through collective rather than individual rights and by protecting TCRs usually left out in conservative, western-style IP-based systems. Under the Framework Treaty, the traditional owners of ICH are thus treated as de facto custodians of ICH - an approach already advocated in early works on cultural rights of indigenous people [22].

On renewed initiative of Trade Ministers, and with support from the World Intellectual Property Organization (WIPO), the Traditional Biological Knowledge, Innovations and Practices (TBKIP) Model Law was endorsed in 2008. The main driving force behind this initiative was the realization of the important role that TK plays in resource management, the sustainable use of biodiversity and food security in Pacific societies. An additional catalyst was the growing concern regarding illicit uses and misappropriation of TK in the Pacific as well as the awareness of the potential economic damage of such practices. A Member of Vanuatu Parliament, MP Regenvanu, recently voiced his concern by stating that "a number of entities are continuing to patent genetic material from Vanuatu presumably without any access and benefit sharing agreements, or consideration of the rights in identifying these plants and animals as potential sources of pharmaceuticals [23]. And while Vanuatu Parliament is expected to debate the WIPO Ratification Bill and the Bill for the International Treaty on Plant Genetic Resources for Food and Agriculture (Ratification) Act in this First Ordinary Session in 2013, according to a source at the Ministry of Finance and Economic Management, the loss of revenue due to illicit bio-prospecting activities without any benefit-sharing agreement is currently estimated in Vanuatu alone at 60 million US dollar over the past decade [24].

The Model Law is expected to form a considerable basis for the legislation currently debated in Vanuatu and elsewhere in the Pacific. Similar to the Framework Treaty 2002, the Model Law determines that the traditional owners of TBKIPs are the holders of moral rights in their TBKIPs and that these comprise the right of attribution of ownership; the right not to have ownership of TBKIPs falsely attributed; and the right not to have their TBKIPs subject to derogatory treatment. The Model Law further stipulates that where TBKIPs are used for a 
commercial purpose, there is a requirement for fair and equitable benefit sharing arrangements (monetary or nonmonetary compensation) with the traditional owners. It remains to be seen how and to what extent these provisions will be mirrored in national legislation over the next couple of years. However, the recent Pacific move towards accession of WIPO and signature of UNESCO Treaties is expected to have an impact via stronger IP-based legislative regimes in opposition to regimes based to a greater extent on customary law. For the sake of a balanced approach to ICH protection, the latter should thus receive a more prominent place in regional frameworks than is the case to date.

In December 2009, the Traditional Knowledge Action Plan for the Pacific region, based on directives of Pacific Trade Ministers, has been launched at a Traditional Knowledge workshop convened by the Pacific Islands Forum Secretariat (PIFS) and World Intellectual Property Rights Organisation (WIPO) in Fiji. Responsibility for the implementation of the TK Action Plan rests with the PIFS working in close collaboration with the Trade Com - an ACP Group Programme financed by the European Development Fund (EDF), aiming at support for the formulation of trade policies, trade negotiations and the implementation of international trade agreements - WIPO, the Secretariat of the Pacific Community (SPC) and the South Pacific Regional Environmental Programme (SPREP). Heralded as "milestone development for the region" [25], the Action Plan's main objective is twofold. It aims at the development of national systems of protection setting out new rights and obligations in TK that will complement existing forms of protection for intellectual property (Phase I) and development of cultural industries in the region through activities to promote the commercialization of TK (Phase II). The Action Plan itself stipulates that "[1]egal certainty of ownership and management of resources will be established, providing security and predictability for economic developments in business, technology and investment, local creativity and innovation." The strong commercial focus on TK derives from the tradedriven context of the Action Plan as well as from its founding fathers' IPR agendas.

Phase I of the TK Action Plan resulted in its implementation in a first group of countries consisting of the Cook Islands, Fiji, Kiribati, Palau, Papua New Guinea and Vanuatu. At their May 12, 2012 meeting in the Marshall Islands, the Forum Trade Ministers agreed to extend the priority for Phase II of the TK Action Plan to include technical assistance for the drafting of TK policy and legislative frameworks in PICs. What has been perceived as problematic in this legislation-first, top-down approach is the fact that it was not based consultation with stakeholders [26] - an omission which may result in misinterpretation of rights or, even worse, oversight of rights currently recognized under customary law. At the same time, the Ministers decided most recently to focus on further commercialization of $\mathrm{TK}$ and cultural industries, despite dangers outlined above under the Dream Catcher Syndrome. In the face of its strong commercial focus, the TK Action Plan must thus be seen as an opposite force to the Model Law. By applying western value systems to the protection of amorphous, community-and context-based, living $\mathrm{ICH}$, the Action Plan largely mirrors conservative, IP-based agendas of trade-driven development initiatives led by WIPO or the EU in EPA context. Simultaneously, the commercial focus carries to a large extent the exclusion of customary law from ascertaining IPRs or their enforcement that is largely left to state institutions. Issues created by the state-centered approach of the Action Plan as well as the non-pluralist intake on $\mathrm{ICH}$ protection have both been highlighted by Forsyth [26].

In a most recent move, the MSG Framework Treaty on the Protection of Traditional Knowledge and Expressions of Culture was adopted at the MSG Leaders Summit on 31 March 2011. As members of the Melanesian Spearhead Group of Countries (MSG), the Governments of Fiji, Papua New Guinea, Solomon Islands and Vanuatu, pledged "to protect traditional knowledge holders and owners against any infringement of their rights as recognized by this Treaty (...) and to protect expressions of culture against misappropriation, misuse and unlawful exploitation" [27]. At the time of writing, the MSG Treaty has been approved in principle by its members, but has not been signed by all MSG countries yet; it needs the deposition of two instruments of ratification with the MSG Secretariat for its entry into force. The MSG Framework Treaty is similar to the 2002 Framework Document in scope and subject matter as well as in the allocation of TK ownership or the duration of protection. Its innovation relates to the collaborative element of the MSG Framework Treaty which stipulates in Article 15 cooperation in cross border measures as well as networking of judicial authorities and enforcement agencies. Such collaboration has a potential to develop into an integrated and harmonized approach to TK protection, at least at sub-regional level. This in itself, if executed, would guarantee that customary protection and management practices are included in the legislation of at least the MSG member countries.

\section{WHY EUROPE SHOULD LISTEN IN}

Article 167 of the Treaty on the Functioning of the European Union (Lisbon Treaty) commands the mainstreaming of culture into EU policies in the fields of external relations, development, and trade. The 2007 European Agenda for Culture reinforces the Lisbon Treaty mandate by stating that "culture is increasingly perceived [by the EU] as a strategic factor of political, social and economic development and not in terms of isolated cultural events or showcasing" [28]. In its 2010 progress report on the implementation of the EU Agenda for Culture, the European Commission stressed that next to EU technical and financial assistance, the EU is increasingly concerned with the protection of rights of indigenous people and the promotion of cultural rights in general [29]. In relation to development cooperation, the progress report makes a reference to "living culture and cultural heritage", recognizing them "important for growth, jobs and cultural identity". Furthermore, in cooperation with a UNESCO-managed expert facility, the EU is committed to support the development of an institutional and regulatory framework based on IPRs to "facilitate and respect the commercial exploitation of the [ACP countries'] cultural heritage" [28].

Until the entry into force of the Cotonou Agreement (CA) in 2000 , culture did not appear as a stand-alone issue in EU-ACP relations and was mostly seen through the lens of human resource development or the preservation of natural heritage in ACP countries [30]. Art 27 CA states that the cultural dimension is to be implemented at all levels of development cooperation and in developing cultural industries and enhancing market access opportunities for cultural goods and services. ${ }^{*}$ In

In 2007, the title of Article 27 CA was amended from "cultural development" to "culture and development" to better reflect the role culture plays in general economic development of ACP countries. 
the Pacific, the EU recognized accessibility as the biggest impediment to the development of a "sustainable Pacific arts sector that is valued as a pathway to economic empowerment" [28]. The EU's current efforts - supported by a grant of 713,000 Euro from the 10th European Development Fund and covering the period 2008-2013 - focus on a restructuring of the Pacific cultural sector so that culture is better recognized as a driver of, and a tool for, development. EPAs are one expression of those activities.

In EPAs with ACP countries, the EU addresses culture as a non-trade objective and uses EPA provisions "to promote intellectual property protection standards and ensure that the rights of artists and performers get the protection they deserve" [29]. Usually, IPR-related trade provisions would seek to strengthen IPR enforcement in ACP countries. After all, strong IPR represent a vital interest of European right holders against the background of frequent IP breaches in developing countries with a weak IP (enforcement) regime. In return, the EU is prepared to agree, usually in an additional Protocol to the EPA, on "preferential treatment for developing countries' cultural goods, services and cultural practitioners, outside of the provisions on trade liberalization" [31]. The draft Pacific-EU EPA text of June 2006 is the latest publicly available text and does not contain any IPR-related provisions yet. The 2011 EPA draft text does most probably contain IPR-related provisions that are thought to be similar to the provisions contained in the EU-CARIFORUM EPA. If this is correct, PICs need to be aware that the IP standards required of them will, in part, be above the standards advocated in WIPO treaties and the Trade Related Aspects of Intellectual Property Rights (TRIPS) Agreement of the World Trade Organization (WTO).

As outlined above, PICs are in the midst of formulating regional frameworks for ICH protection and drafting of national legislation has begun. While there has been little debate on the cultural dimension to development or the contribution a cultural protocol may have to sustainable development and service provision in the Pacific [16], there is common agreement that any IPR-related provisions need to take into account the peculiarities of the Pacific context, especially the pluralist nature of Pacific legal systems as well as the living and amorphous characteristics of ICH. Ideally, the Pacific EPA should mirror the key provisions of the 2002 Framework Treaty and the 2011 MSG Model Law in adopting a community rights based approach to ICH and allowing sufficient recognition for already existing models of customary ICH protection and enforcement. Instead of a state-centered approach to ICH as followed in the TK Action Plan, the Pacific EPA should focus on indigenous communities as custodians of ICH. In addition, IPR-related EPA provisions should provide sufficient recognition and address of issues emerging in Pacific communities following commercialization and commodifcation of ICH.

The main challenge relates to the fact that, due to a lack of home-grown expertise in the area of protection of ICH, Pacific governments often have no other choice than to accept IPRrelated proposals as a given. In consequence, IPR provisions in the Pacific EPA will inevitably be removed from the Pacific context and will be often based on preconceived perceptions of a particular system of culture management, exploitation and protection that is biased towards EU's requirements. Without a relation of this external model to the Pacific context, the value of the resulting provisions and the effectiveness of legislation drafted on the basis of western assumptions about ICH will unsurprisingly be limited. The EU could, at a minimum, ensure that Pacific concerns are taken seriously in negotiations of any IPR-related provisions in the Pacific EPA.

Another relevant issue in $\mathrm{ICH}$ protection in the Pacific relates to the orthodox distinction between individual and collective rights and the difficulties state legal systems are facing in protecting the latter via IPR provisions designed to provide protection for individuals. Despite the fact that "[o]ver the past two decades, there has been a gradual shift towards an understanding of cultural rights as a collective right, in addition to an individual right" based on "the progressive global acknowledgement of cultural diversity and difference" as well as "the recognition of rights of indigenous peoples" [32], the Pacific EPA is unlikely to adapt to this shift in IPR-related provisions which are traditionally replicas of western-style IPR standards orientated towards individual ownership of IPRs.

The EPA presents a unique opportunity for the EU to sustain the regional initiatives in Pacific ICH management and protection; it also bears the prospect of support to remedy the fragmented national approaches to ICH via an integrated, harmonized sui generis solution that all PICs can subscribe to. The development dimension of the EPA should ensure that the EPA becomes a tool for contextualized approach to IPRs in the Pacific region, taking into account peculiarities and sensitivities of Pacific ICH. In an open-minded approach, pluralist environments could be seen as enriching the landscape of ICH management options while offering as good a protection to IPRs via customary law as could be achieved otherwise by relying solely on statecentered approaches. The mandate of the CA to respect the development status of EPA partners as well as regional integration initiatives under way seems supportive of an alternative approach to IPR provisions, one that goes beyond market access and effective enforcement. Before setting up a binding IPR regime via the Pacific EPA, the EU should listen in to the words of Boyle in which he expressed the potential impact of IPRs by saying "when you set up property rules in some new space, you determine much about the history that follows" [33].

\section{SELECTED BIBLIOGRAPHY}

1. Serrano, K., Stefanova, M., 2011. Between international law, kastom and sustainable development: Cultural heritage in Vanuatu. Baldaccino, G., Niles, D. (Ed.): Island Futures, Japan, Springer, pp. 19-36.

2. Samoa Law Reform Commission, 2010. The Protection of Samoa's Traditional Knowledge and Expressions of Culture. Issues Paper 08/10.

3. Yahaya, A., 2006. The Scope and Definitions of Heritage: From Tangible to Intangible. International Journal of Heritage Studies, 12 (3), pp. 292-300.

4. Menaka, H.A., 2010. Traditional Knowledge (TK) Of Communities: Protection And Redevelopment In The Face Of Emerging Intellectual Property Rights Regime. Paper presented to the Annual Research Symposium conducted by the University of Jaffna, December 2010.

5. UNESCO, undated. Definition of Intangible Cultural Heritage. http://www.unesco.org (accessed 19 May 2012)

6. UNESCO, 2003. Convention for the Safeguarding of the Intangible Cultural Heritage. 32nd Session of the General Conference, Paris 29 September-17 October 2003.

7. UNESCO, 2011. International Round Table "Intangible Cultural Heritage" - Working definitions, Piedmont, Italy (14 to 17 March 2001). http://www.unesco.org/culture/ich/doc/src/05299.pdf (accessed 22 June 2012)

8. Constitution of Tuvalu 1986. 
9. Constitution of the Republic of the Marshall Islands 1979.

10. Malvatumauri National Council of Chiefs, the Vanuatu Cultural Centre and the Vanuatu Credit Union League, 2005. National Self Reliance Strategy 2020.

11. Vanuatu Government, 2006. Priorities and Action Agenda 2006-2015.

12. Vanuatu Ministry of Education, 2012. Interview with anonymous informant (name and contact details with the author), Port Vila, Vanuatu, 23 February 2012)

13. UK Local Government, 2009. What is the direct economic impact of creative industries?

http://www.idea.gov.uk/idk/core/page.do?pageId=11138810 (accessed 22 June 2012)

14. Kenan Institute Asia, 2009. Economic Contributions of Thailand's Creative Industries, Fiscal Policy Institute. December 2009.

http://www.theglobalipcenter.com/sites/default/files/reports/ documents/Thailand_IP_report_2.pdf (accessed 24 June 2012)

15. Hartley, J., 2005. Creative Industries. Blackwell, London. See also Hesmondhalgh, D., 2002. The cultural industries. Sage, London.

16. Secretariat of the Pacific Community (SPC), 2010. Report of the Meeting on the Regional Consultation on the Cultural Industries, Suva, Fiji

http://www.spc.int/hdp/index2.php?option=com_docman\&t ask $=$ doc_view $\&$ gid $=263 \&$ Itemid $=44$ (accessed $\overline{12}$ June 2012)

17. Osborne, S.D., 2003/2004. Protecting Tribal Stories: The Perils of Propertization. 28 Am. Indian L. Rev., pp. 203-236.

18. Urale, M., 2004. Podium discussion during the Planet IndigenUs festival at Toronto Harbourfront Centre, 21 August 2004.

19. Forsyth, M., 2012. Lifting the Lid on "The Community": Who Has the Right to Control Access to Traditional Knowledge and Expressions of Culture? International Journal of Cultural Property 19, pp. 1-31.

20. Marahare, D., 2004. Towards an equitable future in Vanuatu: The legal protection of cultural property. Journal of South Pacific Law, 8(2).

21. Haira, A., 2006. Developing National Legislation based on the Pacific Model Law 2002, Presentation 03 November 2006.

22. Daes, E-I., 1993. Discrimination against indigenous peoples. Study on the protection of the cultural and intellectual property of indigenous peoples, UNESCO, E/CN.4/Sub.2/1993/28.

23. Vanuatu Daily Post, 2012. www.dailypost.vu (accessed 11 June 2012)

24. Vanuatu Ministry of Finance and Economic Management, 2012. Interview with anonymous informant (name and contact details with the author), Port Vila, Vanuatu, 18 May 2012.

25. Pacific Islands Forum Secretariat, 2010. “TK implementation action plan progressing well". Press Release (86/10) 27th September 2010.

http://www.forumsec.org/pages.cfm/newsroom/pressstatements/2010/tk-implementation-action-plan-progressingwell.html (accessed 19 June 2012)

26. Forsyth, M., 2010. Do you want it giftwrapped? Protecting Traditional Knowledge in the Pacific Islands. Conference Paper presented at the Conference on Trade, Intellectual Property and the Knowledge Assets of Indigenous Peoples: The Developmental Frontier, 8 - 10 December 2010, Wellington, New Zealand.

27. MSG Framework Treaty on the Protection of Traditional Knowledge and Expressions of Culture. (2011)
28. European Commission, 2007. European Agenda for Culture. $\operatorname{COM}(2007) 242$ final.

29. European Commission, 2010. The European Agenda for Culture - progress towards shared goals. SEC(2010) 904.

30. Lomé IV Convention 1995.

31. EU-CARIFORUM Economic Partnership Agreement 2008.

32. Huffer, E., 2006. Cultural Rights in the Pacific - What they mean for Children. http://www.unicef.org/eapro/Cultural_rights_in_the_Pacific what_this_means_for_children.pdf. See also Riley, A., 2000. Recovering Collectivity: Group Rights to Intellectual Property in Indigenous Communities. 18 Cardozo Arts \& Ent. L.J. pp. 175-177.

33. Boyle, J., 2008. The Public Domain: Enclosing the Commons of the Mind. Yale, Yale University Press. 